\title{
ANALISIS TENTANG PENGARUH MOTIVASI INTRINSIK DAN MOTIVASI EKSTRINSIK TERHADAP KINERJA KARYAWAN STUDI KASUS: DI RUMAH SAKIT RAJAWALI DAN STIKES RAJAWALI BANDUNG (YAYASAN KEMANUSIAN BANDUNG INDONESIA)
}

\author{
Fotuho Waruwu \\ Fakultas Ekonomi Universitas Nurtanio Bandung \\ Email: fotuhowaruwu@yahoo.co.id
}

Submitted: Feb 10, 2017; Reviewed: Feb 10, 2017; Accepted: Apr 13, 2017

\begin{abstract}
In order to improve the performance of an employee of an organization, such as managers and supervisors should give more attention to the motivation level of their subordinates. The managers should be pay attention to their employee's wants and needs, the strength of his subordinates and set goals in order to satisfy their own needs. Representation of employees' interests in RS Rajawali and STIKES Rajawali believed to encourage employee's motivation to work harder and better so that it can optimize any potential. The aim of this study is to determine the effect of intrinsic and extrinsic motivation either partially or simultaneously on the employee's performance in RS Rajawali and STIKES Rajawali. Object of this study were all employees works in RS Rajawali, 122 people from a variety of occupations such as doctors, nurses, to the non-medical staff in STIKES Rajawali, 28 people consist of lecturers and administrative staff. This type of research is descriptive quantitative research, research on the data collected and expressed in the form of numbers, although the form of qualitative data as well as supporting, such as the words or phrases that are arranged in the questionnaire, the results sentences of consultation or the interview between researcher and informant. The results showed that intrinsic motivation (82,20\%) and extrinsic motivation (83,56\%) has an influence on the performance of employees $(76,42 \%)$ in RS Rajawali and STIKES Rajawali Bandung. However from both motivations, the most responses which give an affect of the employee's motivation are reward or salary.
\end{abstract}

Keywords: Extrinsic; Intrinsic; Motivation; Performance

\section{PENDAHULUAN}

Untuk dapat meningkatkan semangat serta kegairahan kerja karyawan, maka pimpinan perusahaan harus mengetahui apa saja yang diinginkan, atau yang dibutuhkan oleh karyawan. Apabila hal tersebut dapat dipenuhi oleh pimpinan perusahaan, maka diharapkan dapat meningkatkan kepuasan para karyawan. Untuk itu sudah menjadi kewajiban bagi seorang pimpinan untuk mencari hal-hal apa saja yang diinginkan atau dibutuhkan oleh karyawan sebuah perusahaan. Semangat dan kegairahan kerja tersebut yang menjadi motivasi bagi karyawan ketika bekerja.

Motivasi kemudian dianggap penting karena hal ini yang mendorong kerja keras dan antusiasme karyawan untuk mencapai produktivitas kerja yang tinggi. Motivasi merupakan subyek yang penting bagi pimpinan, karena menurut definisi pimpinan harus bekerja dengan dan melalui orang lain, pimpinan perlu memahami orang-orang berperilaku tertentu agar dapat mempengaruhinya untuk bekerja sesuai yang diinginkan organisasi (Siagian, 2004:172). Motivasi tidak dapat diamati secara langsung, 
tetapi dapat diinterpretasikan dari tingkah lakunya. Dengan mengetahui perilaku manusia, apa sebabnya orang mau bekerja dan kepuasankepuasan apa yang dinikmatinya karena bekerja, maka seorang pimpinan akan lebih mudah memotivasi bawahannya.

Melihat fenomena semakin rendahnya motivasi karyawan dalam bekerja serta disisi lain ada juga sebagian karyawan yang punya motivasi tinggi dalam bekerja walaupun telah mencapai usia pensiun maka penulis tertarik untuk meneliti lebih jauh tentang alasan dari permasalahan tersebut.

Motivasi dapat disimpulkan sebagai keinginan, kesediaan, dorongan dan kerelaan seseorang untuk melakukan tindakan-tindakan yang optimal dengan mengeluarkan kemampuan terbaik untuk mencapai tujuan perusahaan serta memenuhi kebutuhan individu (Terry, 2000:94; Robbins, 2002:251; Gibson, 2000:251).

Motivasi muncul dari dalam diri manusia, tetapi keberadaannya karena rangsangan atau dorongan oleh adanya unsur lain, dalam hal ini adalah dorongan untuk mencapai tujuan. Organisasi harus membina motivasi karyawan melalui proses pemenuhan kebutuhan. Kebutuhan yang belum terpuaskan akan menimbulkan ketegangan yang dapat menstimulasi dorongan tertentu pada individu yang bersangkutan.

Dalam rangka meningkatkan kinerja karyawan sebuah organisasi, atasan seperti manajer dan supervisor haruslah memberikan perhatian yang lebih pada level motivasi dari bawahan-bawahannya. Para manajer memperhatikan apa keinginan dan kebutuhan karyawannya, kekuatan yang dimiliki bawahannya serta sasaran-sasaran yang ditetapkan dalam rangka memuaskan kebutuhan diri mereka sendiri (Densten, 2002:17).

Demikian juga dijelaskan dalam teori Hamzah (2008:82) bahwa orang dalam melaksanakan pekerjaannya dipengaruhi oleh dua faktor, yaitu faktor motivasional dan faktor hygiene. Faktor motivasional adalah hal-hal yang mendorong berprestasi yang sifatnya intrinsik sedangkan faktor hygiene adalah faktor-faktor yang sifatnya ekstrinsik.

Beberapa faktor tersebut bisa dikatakan semacam self reward yang pada akhirnya meningkatkan motivasi kerja dari karyawan. Namun sebelum mendapatkan reward atas diri sendiri karena telah melakukan suatu hal yang penting bagi perusahaan, karyawan harus terlebih dahulu menetapkan standar self rewardnya terutama dalam hal pemberian pelayanan kepada publik (Koch, et al., 2012:3).

Kebijakan dan peraturan yang ditetapkan oleh RS Rajawali dan STIKES Rajawali, hendaknya dilaksanakan dengan cermat dan hatihati, karena ternyata kebijakan dan peraturan yang ditetapkan tersebut tidak hanya dapat menguntungkan perusahaan, tetapi juga mampu memberikan kontribusi yang nyata bagi karyawannya. Terwakilinya kepentingan karyawan dalam RS Rajawali dan STIKES Rajawali diyakini dapat mendorong motivasi kerja karyawan untuk bekerja dengan giat dan lebih baik sehingga dapat mengoptimalkan setiap potensi yang dimilikinya. Begitu juga dengan hal-hal lainnya yang menyangkut hubungan antara atasan/bawahan/rekan sekerja yang juga memberikan pengaruh terhadap motivasi kerja karyawan sehingga lebih memacu semangat dalam bekerja.

Beberapa hasil penelitian sebelumnya yang meneliti tentang motivasi antara lain penelitian yang dilakukan Bodur (2002:25) yang menemukan bahwa tingkat kepuasan seluruh staff pusat kesehatan masyarakat di Turki tergolong rendah disebabkan oleh kondisi kerja yang tidak nyaman, kecilnya peluang mengembangkan karir dan gaji yang terlalu rendah. Matthews (2006:31) menemukan bahwa tingkat kepuasan dipengaruhi oleh motivasi (lingkungan kerja fisik/tempat kerja yang baik, system penggajian yang adil, pengharapan, peluang pengembangan karir, pekerjaan yang pantas). Sedangkan Borzaga (2006:28) menemukan bahwa faktor intrinsik dan sikap terhadap hubungan kerja yang paling berpengaruh terhadap kinerja dan kepuasan karyawan itu sendiri.

Berdasarkan kenyataan tersebut, maka penting artinya bagi RS Rajawali dan STIKES Rajawali untuk dapat mengetahui faktor-faktor apa saja yang menjadi kebutuhan karyawannya sehingga dapat dijadikan acuan untuk menghidupkan motivasi kerja karyawannya agar dapat mencapai tujuan yang ditetapkan perusahaan maupun tujuannya sendiri yang bergantung pada kinerja karyawan tersebut.

Oleh karena itu dalam penelitian ini penulis ingin mengetahui lebih lanjut bagaimana pengaruh motivasi intrinsik dan ekstrinsik yang dirasakan karyawan terhadap kinerja kerjanya.

Motivasi intrinsik menurut Reinholt (2006:4) dalam Hamzah (2008:76) adalah perilaku yang berdasarkan perasaan bahwa seseorang harus memiliki perilaku yang tidak 
berdasarkan peraturan-peraturan, norma serta prinsip-prinsip, serta tanpa adanya keinginan untuk mendapatkan penghargaan. Hal ini kemudian menjelaskan keinginan seseorang untuk bertindak sewajarnya dan berkembang melalui proses sosialisasi.

Sedangkan menurut Bakay dan Huang (2010:4) motivasi ekstrinsik merupakan langkahlangkah yang dilakukan untuk mencapai tujuannya, memenuhi sasarannya serta mendapatkan penghargaan atau menyelesaikan deadline yang dimilikinya.

Dalam penelitian ini, variabel yang digunakan adalah variabel motivasi kerja yang terdiri dari motivasi intrinsik (Prestasi (Achievement); Komitmen terhadap organisasi; Pengakuan (Recognition); Pekerjaan Itu Sendiri (The work it self); Tanggung Jawab (Responsibility); Pengembangan Potensi Individu (Advancement), (Hamzah, 2008:77-81) dan motivasi ekstrinsik (Kompensasi, Gaji atau Imbalan (wages salaries); Umpan-balik; Kondisi kerja (working condition); Kebijaksanaan dan Administrasi Perusahaan (Company policy and administration); Hubungan antar Pribadi (Interpersonal Relation); Kepemimpinan; Kualitas Supervisi), Hamzah (2008:82), dan serta variabel dependennya adalah kinerja karyawan di RS Rajawali dan STIKES Rajawali Bandung.

Penentuan tujuan suatu organisasi merupakan strategi untuk meningkatkan kinerja. Tujuan ini akan memberikan arah dan mempengaruhi bagaimana seharusnya perilaku kerja yang diharapkan organisasi dari setiap personel. Maka melalui analisa pengaruh variabel independen motivasi intrinsik dan ekstrinsik secara parsial dan simultan terhadap kinerja karyawan, maka penulis berharap akan memperoleh hasil yang menunjukkan apa yang perlu diperhatiakan dan ditingkatkan oleh manajemen RS Rajawali dan STIKES Rajawali. Penilaian secara kuantitatif dan kualitatif standar kinerja untuk setiap tugas dan jabatan personel yang memegang peranan penting. Untuk lebih jelasnya digambarkan pada skema model penelitian berikut ini:

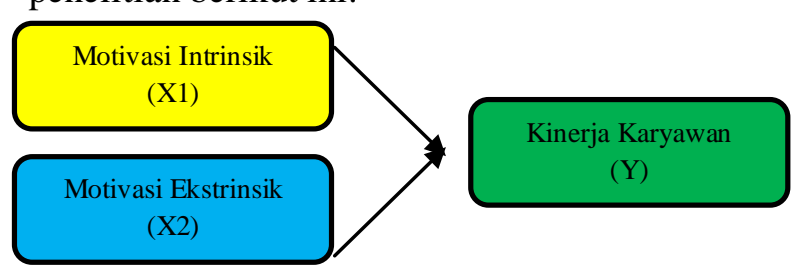

Gambar 1. Model penelitian pengaruh motivasi intrinsik dan ekstrinsik secara parsial dan simultan terhadap kinerja karyawan

\section{HIPOTESIS}

Berdasarkan rerangka pemikiran diatas, maka hipotesisnya adalah:

1. $\mathrm{X}_{1}$ : Faktor intrinsik mempengaruhi kinerja kerja karyawan di RS Rajawali dan STIKES Rajawali.

2. $\mathrm{X}_{2}$ : Faktor ekstrinsik mempengaruhi kinerja kerja karyawan di RS Rajawali dan STIKES Rajawali.

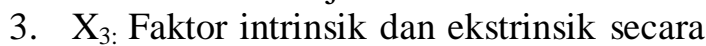
simultan mempengaruhi kinerja kerja karyawan di RS Rajawali dan STIKES Rajawali.

\section{POPULASI DAN SAMPEL}

Cara pengambilan sampel dalam penelitian ini adalah menggunakan Sampling Jenuh. Sampel yang digunakan dalam penelitian ini adalah seluruh karyawan RS Rajawali dan STIKES Rajawali dengan harapan sebanyak 150 orang bersedia menjadi responden dan bersedia mengembalikan lembar kuisioner yang akan di bagikan.

\section{HASIL PENELITIAN}

Karakteristik responden terdiri dari jenis kelamin, usia, status pernikahan, dan lama bekerja seperti disajikan pada gambar berikut.

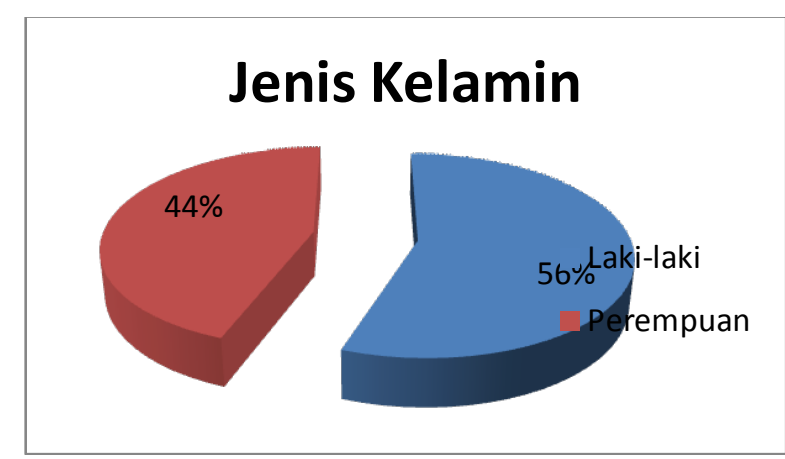

Gambar 2. Jenis Kelamin responden

Gambar di atas menunjukkan jenis kelamin responden yang menjadi sampel dalam penelitian ini. Sebanyak 84 orang (56\%) responden berjenis kelamin laki-laki sedangkan sebanyak 66 orang (44\%) responden berjenis kelamin perempuan 


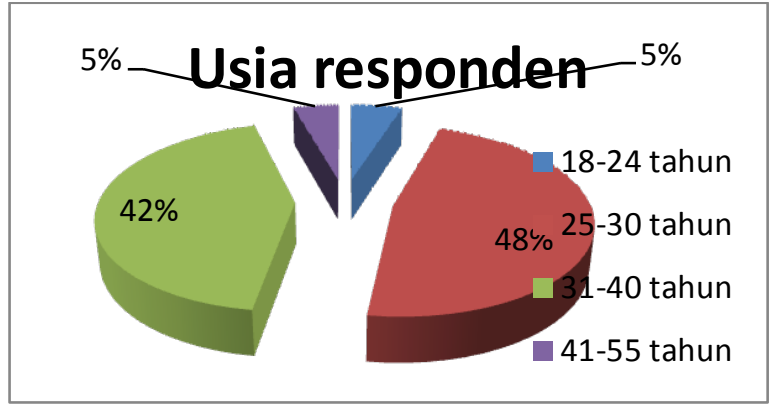

Gambar 3. Usia Responden

Gambar di atas menunjukkan usia responden dalam penelitian ini. Sebagian besar responden atau 72 orang $(48 \%)$ berusia diantara 25 sampai dengan 30 tahun.

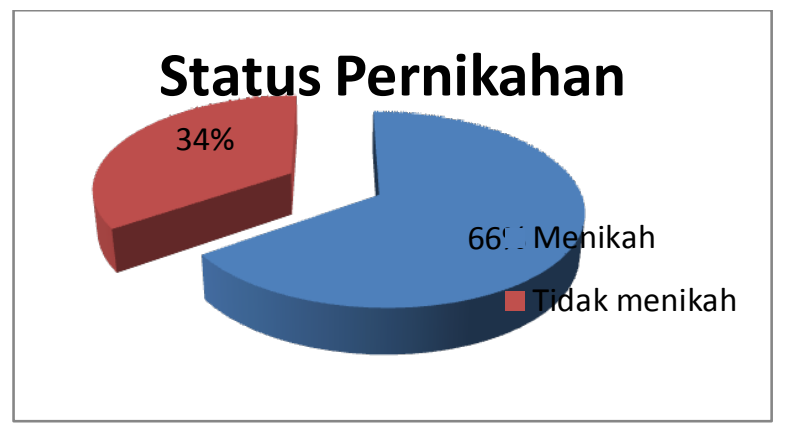

Gambar 4. Status Pernikahan Responden

Berdasarkan hasil penelitian diketahui bahwa mayoritas responden atau 99 orang (66\%) dari keseluruhan responden berstatus sudah menikah sedangkan sisanya sebanyak 51 orang (34\%) berstatus belum menikah.

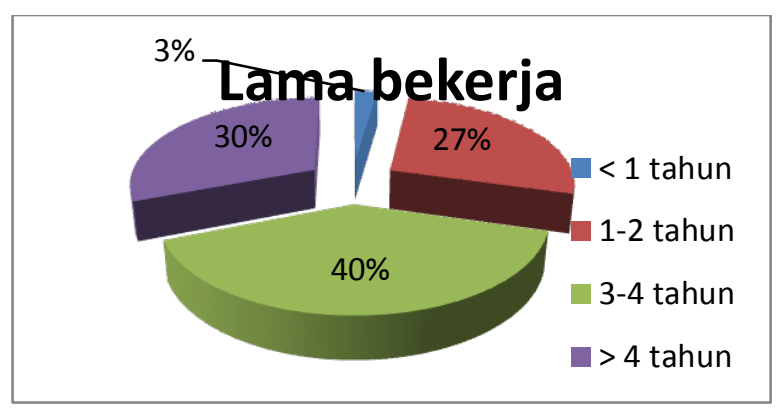

Gambar 5. Lama Bekerja

Gambar di atas menunjukkan lama bekerja responden dalam penelitian ini, baik di RS Rajawali maupun di STIKES Rajawali. Sebanyak 60 orang (40\%) atau hampir dari setengah responden sudah bekerja selama 3 sampai dengan 4 tahun, sedangkan sebanyak 45 orang (30\%) responden sudah bekerja lebih dari 4 tahun.

\section{Uji Validitas}

Pengujian ini dilakukan untuk menguji kevalidan setiap item pernyataan dalam mengukur variabelnya. Pengujian validitas dalam penelitian ini dilakukan dengan cara mengkorelasikan skor masing-masing pertanyaan item yang ditujukan kepada responden dengan total skor untuk seluruh item. Teknik korelasi yang digunakan untuk menguji validitas butir pernyataan dalam penelitian ini adalah dengan korelasi spearman brown.

Dalam buku Azwar (2010) disebutkan apabila nilai koefisien korelasi butir item pernyataan yang sedang diuji lebih besar dari 0,30 maka dapat disimpulkan bahwa item pernyataan tersebut merupakan konstruksi (construct) yang valid. Adapun hasil uji validitas untuk kuesioner penelitian adalah sebagai berikut:

Tabel 1. Uji Validitas Motivasi

\begin{tabular}{cccc}
\hline $\begin{array}{c}\text { Butir } \\
\text { pernyataan }\end{array}$ & $\begin{array}{c}\text { Indeks } \\
\text { validitas }\end{array}$ & $\begin{array}{c}\text { Nilai } \\
\text { kritis }\end{array}$ & Keterangan \\
\hline Item 1 & 0,584 & 0,30 & Valid \\
Item 2 & 0,473 & 0,30 & Valid \\
Item 3 & 0,741 & 0,30 & Valid \\
Item 4 & 0,661 & 0,30 & Valid \\
Item 5 & 0,483 & 0,30 & Valid \\
Item 6 & 0,478 & 0,30 & Valid \\
Item 7 & 0,446 & 0,30 & Valid \\
Item 8 & 0,684 & 0,30 & Valid \\
Item 9 & 0,743 & 0,30 & Valid \\
Item 10 & 0,455 & 0,30 & Valid \\
Item 11 & 0,564 & 0,30 & Valid \\
Item 12 & 0,672 & 0,30 & Valid \\
Item 13 & 0,732 & 0,30 & Valid \\
Item 14 & 0,574 & 0,30 & Valid \\
Item 15 & 0,603 & 0,30 & Valid \\
Item 16 & 0,574 & 0,30 & Valid \\
Item 17 & 0,638 & 0,30 & Valid \\
Item 18 & 0,743 & 0,30 & Valid \\
Item 19 & 0,528 & 0,30 & Valid \\
Item 20 & 0,619 & 0,30 & Valid \\
Item 21 & 0,574 & 0,30 & Valid \\
Item 22 & 0,546 & 0,30 & Valid \\
Item 23 & 0,488 & 0,30 & Valid \\
\hline Sumber : Hasil pengolahan kuesioner &
\end{tabular}


Tabel 2. Uji Validitas kinerja Karyawan

\begin{tabular}{cccc}
\hline $\begin{array}{c}\text { Butir } \\
\text { pernyataan }\end{array}$ & $\begin{array}{c}\text { Indeks } \\
\text { validitas }\end{array}$ & $\begin{array}{c}\text { Nilai } \\
\text { kritis }\end{array}$ & Keterangan \\
\hline Item 1 & 0,574 & 0,30 & Valid \\
Item 2 & 0,493 & 0,30 & Valid \\
Item 3 & 0,658 & 0,30 & Valid \\
Item 4 & 0,357 & 0,30 & Valid \\
Item 5 & 0,584 & 0,30 & Valid \\
Item 6 & 0,668 & 0,30 & Valid \\
Item 7 & 0,742 & 0,30 & Valid \\
Item 8 & 0,592 & 0,30 & Valid \\
Item 9 & 0,446 & 0,30 & Valid \\
Item 10 & 0,546 & 0.30 & Valid \\
Item 11 & 0,573 & 0.30 & Valid \\
Item 12 & 0,649 & 0.30 & Valid \\
Item 13 & 0,781 & 0.30 & Valid \\
Item 14 & 0,581 & 0.30 & Valid \\
\hline Sumber : Hasil Pengolahan Kuesioner &
\end{tabular}

Berdasarkan hasil pengolahan kuesioner pada kedua tabel di atas, terlihat bahwa nilai indeks validitas setiap butir pernyataan lebih besar daripada 0,30 sehingga dapat disimpulkan bahwa seluruh butir pernyataan pada semua variabel yang digunakan dalam penelitian ini adalah valid dan layak digunakan pada analisis selanjutnya.

\section{Analisis Deskriptif}

Deskripsi dan penelitian berguna untuk melihat kecenderungan responden dalam menjawab setiap item pertanyaan dan membantu pembahasan penelitian. Kecenderungan responden dikategorikan dalam skala Likert dengan alternatif jawaban mulai dari Sangat Setuju (SS), Setuju (S), Ragu-ragu (R), Tidak Setuju (TS), Sangat Tidak Setuju (STS).

Analisis deskriptif dilakukan per sub variabel, berdasarkan data yang didapat dari angket yang disebarkan kepada 150 orang responden. Dalam data penelitian ini terdiri dari variabel motivasi intrinsik $\left(\mathrm{X}_{1}\right)$, motivasi ekstrinsik (X2), dan kinerja karyawan (Y). Untuk memudahkan analisis korelasional, maka peneliti membuat klasifikasi data dengan menggunakan skala likert dan dilakukan analisis deskriptif per sub variabel. Masing-masing pertanyaan yang telah dijawab oleh responden akan direkapitulasi dan dihitung jumlah skor per item nya. Selanjutnya skor tersebut akan diakumulasikan sebagai skor akumulasi per sub variabel.

Skor tertinggi masing-masing sub variabel dapat dihitung dengan:
Skor ideal (SS): Jumlah pertanyaan x 5 (bobot tertinggi) $\mathrm{x}$ jumlah responden

Skor terendah (STS): Jumlah pertanyaan $\mathrm{x} 1$ (bobot terendah) $\mathrm{x}$ jumlah responden

Dalam range skor tersebut, dapat dilihat posisi kecenderungan jawaban responden terhadap sub variabel penelitian. Persentase skor kumulatif per sub variabel dapat dihitung dengan:

$$
\text { Jumlah \% }=\frac{\text { Skor kumulatif }}{\text { Skor ideal }} \times 100 \%
$$

Melalui persentase tersebut, dapat diketahui kriteria interpretasi skor, seperti dikemukakan dalam Riduwan:
$0 \%-20 \%$
: Sangat Lemah
$21 \%-40 \% \quad$ : Lemah
$41 \%-60 \% \quad$ : Cukup
$61 \%-80 \% \quad$ : Kuat
$81 \%-100 \% \quad$ : Sangat Kuat

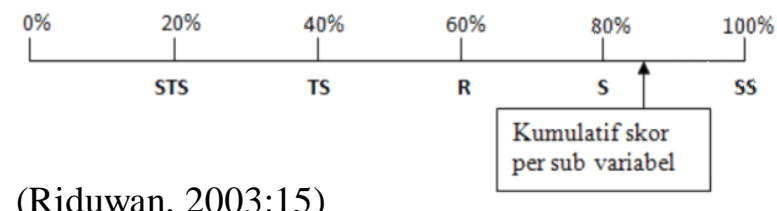

(Riduwan, 2003:15)

Berdasarkan skor jawaban dari kuisioner untuk kategori dari sub variabel motivasi intrinsik, maka dihitung dalam batas interval dengan cara:

- Skor tertinggi (SS) $=5 \times 16$ (jumlah pertanyaan) $\mathrm{x} 150$ (jumlah responden) = 12000

- Skor terendah (STS) $=1 \times 16$ (jumlah pertanyaan) $\mathrm{x} 150$ (jumlah responden) = 2400

Berdasarkan data yang diperoleh dari 150 orang responden maka motivasi intrinsik masuk ke dalam kategori:

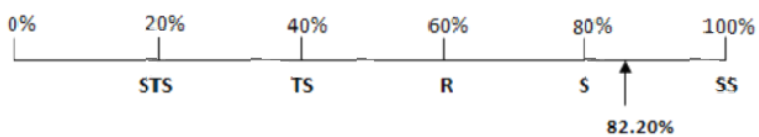

Jumlah persentase skor kumulatif motivasi intrinsik, $(9865 / 12000) \times 100 \%=82.20 \%$. Dengan begitu motivasi intrinsik masuk ke dalam kategori yang sangat kuat (81\% - 100\%). Hal ini menunjukkan bahwa motivasi intrinsik merupakan salah satu faktor atau variabel yang bisa memiliki pengaruh terhadap kinerja karyawan. 
Untuk kategori dari sub variabel motivasi ekstrinsik, maka dihitung dalam batas interval dengan cara:

- Skor tertinggi (SS) = 5 x 7 (jumlah pertanyaan) $\times 150$ (jumlah responden) = 5250

- Skor terendah (STS) $=1 \times 7$ (jumlah pertanyaan) $\mathrm{x} 150$ (jumlah responden) = 1050

Berdasarkan data yang diperoleh dari 150 orang responden maka motivasi ekstrinsik masuk ke dalam kategori:

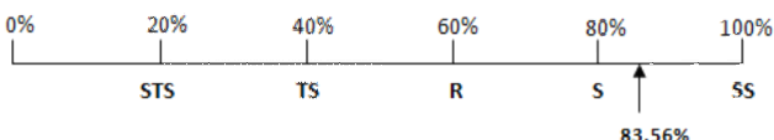

Jumlah persentase skor kumulatif motivasi ekstrinsik, $(4387 / 5250) \times 100 \%=83.56 \%$. Dengan begitu motivasi ekstrinsik masuk ke dalam kategori yang sangat kuat (81\% - 100\%). Hal ini menunjukkan bahwa motivasi ekstrinsik merupakan salah satu faktor atau variabel yang bisa memiliki pengaruh terhadap kinerja karyawan.

Untuk kategori dari sub variabel kinerja karyawan, maka dihitung dalam batas interval dengan cara:

- Skor tertinggi (SS) $=5 \times 14$ (jumlah pertanyaan) $\mathrm{x} 150$ (jumlah responden) = 10500

- Skor terendah (STS) $=1 \times 14$ (jumlah pertanyaan) $\mathrm{x} 150$ (jumlah responden) = 2100

Berdasarkan data yang diperoleh dari 150 orang responden maka kinerja karyawan masuk ke dalam kategori:

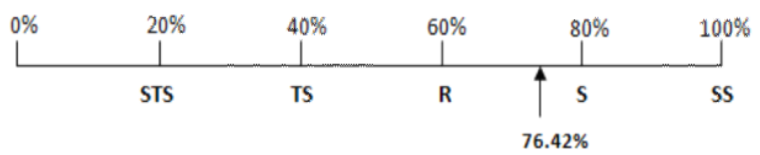

Jumlah persentase skor kumulatif kinerja karyawan, (8025/10500) x 100\% = 76.42\%. Dengan begitu kinerja karyawan masuk ke dalam kategori yang kuat $(61 \%$ - 80\%). Hal ini menunjukkan bahwa kinerja karyawan di RS Rajawali dan STIKES Rajawali sudah baik.

Model regresi yang baik adalah distribusi data normal atau mendekati normal. Dimana dalam penelitian ini digunakan metode Kolmogorov-Smirnov yang dilakukan dengan bantuan program SPSS 17.00 for windows. Pengambilan keputusan pada pengujian ini dilakukan sebagai berikut:
- Asymp. Sig $<0.05=$ Distribusi Tidak Normal

- Asymp. Sig $>0.05=$ Distribusi Normal

Tabel 3. Uji Normalitas Data

\begin{tabular}{llrrr}
\hline \multicolumn{4}{c}{ One-Sample Kolmogorov-Smirnov Test } & \\
& & Intrinsik & Ekstrinsik & \multicolumn{1}{c}{ Kincrja } \\
$\mathrm{N}$ & & 200 & 200 & 200 \\
Normal Parameters & Mean & 83.3294 & 48.0706 & 52.0353 \\
& Std. Deviation & 8.35719 & 6.25412 & 6.70722 \\
Most Extreme Differences & Absolute & .069 & .126 & .112 \\
& Positive & .069 & .081 & .112 \\
& Negative & -.069 & -.126 & -.100 \\
Kolmogorov-Smirnov Z & & .635 & 1.161 & 1.030 \\
Asymp. Sig. (2-tailed) & .814 & .135 & .239 \\
a. Test distribution is Normal. & & & \\
b. Calculated from data. & & & & \\
\hline
\end{tabular}

Berdasarkan tabel output uji kolmogorovsmirnov di atas, diperoleh informasi bahwa nilai signifikansi signifikansi (Asymp. Sig) Kolmogorov-Smirnov Test variabel independen $\left(\mathrm{X}_{1}\right)$ yaitu Intrinsik memiliki nilai Asymp. 0,814, variabel independen $\left(\mathrm{X}_{2}\right)$ yaitu ekstrinsik memiliki nilai signifikansi 0,135 , variabel dependen (Y) yaitu Kinerja karyawan memiliki nilai signifikansi 0,3239 Ketiga variabel memiliki nilai Asymp. Sig. (2-tailed) > 0,05, sehingga dapat disimpulkan bahwa seluruh variabel tersebut memiliki data yang berdistribusi normal.

Pengujian secara parsial bertujuan untuk menguji pengaruh signifikansi antara variabel bebas terhadap variabel terikat secara individual, berikut uji hipotesis secara parsial:

\section{Tabel 4}

Coefficients $^{\mathrm{a}}$

\begin{tabular}{|c|c|c|c|c|c|c|}
\hline & \multirow{2}{*}{ Model } & \multicolumn{2}{|c|}{ Unstandardized Coefficients } & \multirow{2}{*}{$\begin{array}{l}\text { Standardize } \\
\text { d } \\
\text { Coefficients } \\
\text { Beta }\end{array}$} & \multirow{2}{*}{$\mathbf{t}$} & \multirow{2}{*}{ Sig. } \\
\hline & & B & Std. Error & & & \\
\hline \multirow{3}{*}{1} & (Constant) & .311 & 2.009 & & .155 & .877 \\
\hline & Intrinsik & .077 & .059 & .096 & 1.303 & .026 \\
\hline & Ekstrinsik & .942 & .079 & .878 & 11.859 & .000 \\
\hline \multicolumn{7}{|c|}{ a. Dependent Variable: Kinerja } \\
\hline
\end{tabular}

a. Pengaruh Motivasi Intrinsik Terhadap kinerja karyawan

Hipotesis :

Ho: Motivasi intrinsik secara parsial tidak berpengaruh terhadap kinerja karyawan Ha: Motivasi intrinsik secara parsial berpengaruh terhadap kinerja karyawan Berdasarkan hasil pengujian pada tabel 4 di atas dapat dilihat persamaan regresinya sebagai berikut:

$$
\mathrm{Y}=\operatorname{\rho yx}_{1} \mathrm{X} 1+\mathrm{e}
$$


Nilai signifikansi untuk variabel motivasi intrinsik adalah sebesar 0.026 yang lebih kecil daripada 0.05 sehingga menunjukkan bahwa Ho ditolak yang berarti motivasi intrinsik memiliki pengaruh terhadap kinerja karyawan

\section{b. Pengaruh motivasi ektrinsik terhadap} kinerja karyawan

Ho: Motivasi ekstrinsik secara parsial tidak berpengaruh terhadap kinerja karyawan

Ha: Motivasi ekstrinsik secara parsial berpengaruh terhadap kinerja karyawan

Berdasarkan hasil pengujian pada tabel 4 di atas dapat dilihat persamaan regresinya sebagai berikut:

$$
\mathrm{Y}=\rho \mathrm{yx}_{2} \mathrm{X} 2+\mathrm{e}
$$

Nilai signifikansi untuk variabel motivasi ekstrinsik adalah sebesar 0.000 yang lebih kecil daripada 0.05 sehingga menunjukkan bahwa Ho ditolak yang berarti motivasi ekstrinsik memiliki pengaruh terhadap kinerja karyawan.

\section{Pengujian Hipotesis Secara Simultan antara motivasi intrinsik dan ekstrinsik terhadap kinerja karyawan}

Untuk menguji kedua variabel independen secara bersama-sama maka dilakukan pengujian dengan hipotesis sebagai berikut:

Ho : motivasi intrinsik dan motivasi ekstrinsik secara bersama-sama tidak memiliki pengaruh terhadap kinerja karyawan

Ha : motivasi intrinsik dan motivasi ekstrinsik secara bersama-sama memiliki pengaruh terhadap kinerja karyawan

Untuk pengujian secara simultan, peneliti menggunakan tabel ANOVA yang merupakan hasil olah data menggunakan program SPSS dengan hasil sebagai berikut :

Tabel 5. Uji Simultan

\begin{tabular}{|c|c|c|c|c|c|c|}
\hline \multicolumn{7}{|c|}{ ANOVA $^{\circ}$} \\
\hline \multirow{4}{*}{1} & Model & Stm of Squares & Df & Mean Square & $\mathrm{F}$ & sig \\
\hline & Regression & 427.387 & 2 & 213.693 & 46.533 & $.000^{\circ}$ \\
\hline & Resitual & 6443.488 & 197 & 32.708 & & \\
\hline & Total & 6870875 & 199 & & & \\
\hline & $\begin{array}{l}\text { ors: (Consta } \\
\text { lent Varably }\end{array}$ & $\begin{array}{l}\text { strinsik, hatrinsil } \\
\text { ga }\end{array}$ & & & & \\
\hline
\end{tabular}

Pengujian terhadap hipotesis tersebut dilakukan melalui uji statistik uji $\mathrm{F}$ dengan ketentuan "tolak Ho" jika $\mathrm{F}_{\text {hitung }}$ lebih besar dari $\mathrm{F}_{\text {tabel. }}$ Berdasarkan hasil uji F pada tabel 4.8 dapat dilihat bahwa nilai $\mathrm{F}_{\text {hitung }}$ adalah sebesar 46.533 dimana lebih besar daripada $F_{\text {tabel }}$ (2.26), begitu juga dengan hasil uji signifikansi yaitu sebesar 0.000 yang lebih kecil daripada 0.05. Maka pada tingkat kepercayaan 95\% dapat disimpulkan bahwa Ho ditolak dan Ha diterima, sehingga motivasi intrinsik dan motivasi ekstrinsik secara bersama-sama memiliki pengaruh terhadap kinerja karyawan.

\section{SIMPULAN DAN SARAN \\ Kesimpulan}

Berdasarkan hasil penelitian, maka dapat diambil beberapa kesimpulan sebagai berikut:

1. Motivasi intrinsik memiliki pengaruh terhadap kinerja karyawan di RS Rajawali dan STIKES Rajawali Bandung dengan presentase 82,20\%. Motivasi intrinsik yang dimaksud disini adalah motivasi yang berasal dari dalam diri karyawan itu sendiri, hasil penelitian menunjukkan bahwa semakin besar motivasi intrinsik yang dimiliki karyawan, maka akan semakin baik kinerja karyawan tersebut

2. Motivasi ekstrinsik memiliki pengaruh terhadap kinerja karyawan di RS Rajawali dan STIKES Rajawali Bandung dengan presentase 83,56\%. Motivasi ekstrinsik adalah motivasi yang berasal dari luar diri karyawan, dari beberapa indikator motivasi ekstrinsik, yang mendapatkan tanggapan paling mempengaruhi motivasi karyawan adalah pemberian imbalan atau gaji. Hasil penelitian juga memperlihatkan bahwa semakin besar motivasi ekstrinsik yang didapatkan oleh karyawan maka akan semakin baik kinerja karyawan yang ditunjukkan.

3. Motivasi intrinsik dan ekstrinsik secara bersama-sama atau simultan memiliki pengaruh terhadap kinerja karyawan di RS Rajawali dan STIKES Rajawali Bandung. Sesuai dengan beberapa hasil penelitian lain, penulis membuktikan bahwa motivasi merupakan salah satu faktor yang berpengaruh dalam meningkatkan kinerja karyawan.

Saran penulis untuk RS Rajawali dan STIKES Rajawali antara lain:

1. Motivasi intrinsik merupakan motivasi yang berasal dari diri sendiri dan cukup sulit dibentuk oleh orang lain, namun di 
sini penulis mengusulkan agar para atasan mampu memberikan perhatian, kenyamanan secara merata kepada setiap karyawan,agar dapat membentuk semangat karyawan untuk bekerja dengan lebih baik lagi. Motivasi intrinsik dapat ditingkatkan dengan cara mengetahui tujuan hidupnya, menentukan jalan hidupnya dan belajar untuk menjadi ahli dalam hal-hal penting tersebut.

2. Atasan sebaiknya rutin memperhatikan bagaimana hubungan antara karyawannya agar selalu terjaga dengan baik, dan bila terjadi masalah antar karyawan hendaknya segera diselesaikan agar tidak terjadi ketegangan di dalam kantor yang menyebabkan menurunnya motivasi karyawan yang terlibat untuk bekerja. Komunikasi yang baik dan lancar antara atasan dan bawahan juga sangat penting untuk tetap dijaga dan dibina agar karyawan tidak merasa terasing dan terkucilkan sehingga dengan komunikasi yang baik diharapkan menimbulkan motivasi yang lebih untuk mendapatkan kinerja yang maksimal.

\section{DAFTAR PUSTAKA}

Asmah, G. (2009). Corporate Social Responsibility: Does Motivation Matter?. University of Warwick.

Atinga, R. A. dan Adzei, F. A. (2012). Motivation and Retention of Health Workers in Ghana's District Hospitals: Addressing the Critical Issues. Journal of Health Organization and Management, Vol. 26 Iss: 4

Azwar, S. (2000). Reliabilitas dan Validitas. Yogyakarta: Pustaka Belajar

Bakay, A. and Jun H.. 2010. A Conceptual Model of Motivational Antecedents of Job Outcomes and How Organizational Culture Moderates. SSRN Journal.

Deci, E. L. dan Ryan, R. M. (2000). The "What" and "Why" of Goal Pursuits: Human Needs and the Self-Determination of Behavior. Psychological Inquiry, no.11, 227-268

Densten, I. L. (2002). Leadership and Organizational Culture. Australian Institute of Management and Monash University

Ghozali, I., (2009). Aplikasi Analisis Multivariate Dengan Program SPSS,
Edisi. Keempat. Semarang: Universitas Diponegoro

Gibson, J. L, dan Ivancevich, J. M dan Donelly Jr, J. H., (2000). Organizations: Behaviour, Structure and Process. Boston: McGraw-Hill.

Gomes, F. C., (2003), Manajemen Sumber Daya Manusia, Penerbit Andi,. Yogyakarta

Hamzah, U. B. (2008). Teori Motivasi dan Pengukurannya, Jakarta: Bumi Aksara

Kinman, G. dan Russell K. (2001). The Role of Motivation to Learn in Management Education. Journal of Workplace Learning, Volume 13 No.4

Koch, A. K., Julia N., Anton S. and Jeroen V. (2012). Self Rewards and Personal Motivation. Economic Working Papers. July $4^{\text {th }} 2012$.

Leshabari, M. T., Eustace P. Y., and Naboth M.. (2008). Motivation pf Health Care Workers in Tanzania: A Case Study of Muhimbili National Hospital. East African Journal of Public Health Vol. 5 April

Mallary, G., (2003). SPSS For Windows Step by Step: A Simple Guide and Reference. Boston: Allyn and Bacon

Malhotra. (2010). Riset Penelitian. Jakarta: Gramedia Pustaka Utama

Mangkunegara, A. A. (2001), Manajemen Sumber Daya Manusia Perusahaan. Bandung: Remaja Rosdakarya.

Manullang, M. (2005). Manajemen Sumber Daya Manusia. Yogyakarta: Penerbit BPFE

Ndraha, T. (2005) Teori Budaya Organisasi, Jakarta: BKU Ilmu Pemerintahan

Prawirosentono, S. (2005). Kebijakan Kinerja Karyawan. Yogyakarta: BPFE

Reinholt, M. (2006). No More Polarization, Please! Towards a More Nuanced Perspective on Motivation in Organizations. SMG Working Paper no. 9

Rivai, V. (2005). Manajemen Sumber Daya Manusia Untuk Perusahaan. Jakarta: Raja Grafindo Persada

Robbins, S. P., (2002). Organizational Behaviour, $9^{\text {th }}$ Edition. New Jersey: Prentice-Hall, Inc.

Sarwoto. (2000). Dasar-dasar Manajemen Organisasi. Jakarta: Ghalia

Susbandono. (2006). Motivasi: Bagaimana Cara Meningkatkannya. Jakarta: Penerbit HC

Sekaran, U. (2006). Metodologi Penelitian Untuk Bisnis. Jakarta: Salemba Empat 
Siagian, S. (2004). Manajemen Abad 21. Jakarta: Bumi Aksara

Sugiyono. (2002). Metode Penelitian Administrasi. Bandung: CV Alfabeta

Sugiyono. (2009). Metode Penelitian Kuantitatif dan Kualitatif. Bandung: CV. Alfabeta

Sukmadinata, N. S. 2006. Metode Penelitian Pendidikan. Bandung: Remaja Rosdakarya

Terry, G.R. (2000). Principle Of Management, Disadur Oleh Winardi. Bandung: Alumni

Timpe, D. (2000). Seri Manajemen Sumber Daya manusia, Cetakan ke-4. Jakarta: PT Elex Media Komputindo

Winardi. J, (2001). Motivasi \& Pemotivasian dalam Manajemen. Jakarta: Rajawali Pers 
Jurnal Manajemen Maranatha — Vol. 16 Nomor 2, Mei (2017) 